\title{
Original
}

Journal of Hard Tissue Biology 22[2] (2013) p215-220 C 2013 The Hard Tissue Biology Network Association Printed in Japan, All rights reserved. CODEN-JHTBFF, ISSN 1341-7649

\section{Characteristics and Effects of Muscle Fibers surrounding Lingual Carcinoma}

\author{
Koji Sakiyama $^{1)}$, Shota Takizawa ${ }^{1,2)}$, Yasuhiko Bando ${ }^{1)}$, Katsuyuki Inoue ${ }^{2)}$, Au Sasaki ${ }^{3)}$, Katsuhide Kurokawa ${ }^{4)}$ \\ Yoshiaki Shimoo( ${ }^{5)}$ Masafumi Suzuki's), Shinichi Abe ${ }^{5)}$ and Osamu Amano() \\ ${ }^{1)}$ Division of Anatomy, Department of Human Development and Fostering, Meikai University School of Dentistry, Saitama, Japan \\ ${ }^{2)}$ Division of Maxillofacial-2, Department of Diagnostic and Therapeutic Sciences, Meikai University School of Dentistry, Saitama, \\ Japan \\ ${ }^{3}$ Division of Orthodontics, Department of Human Development and Fostering, Meikai University School of Dentistry, Saitama, \\ Japan \\ ${ }^{4)}$ Department of Sports Dentistry, Tokyo Dental College, Chiba, Japan \\ ${ }^{5}$ Department of Anatomy, Tokyo Dental College, Chiba, Japan
}

(Accepted for publication, February 18, 2013)

\begin{abstract}
It has been suggested that dysphagia caused by excision of carcinoma of the tongue may be affected by the hypofunction of the surrounding muscle tissues, as well as by tissue defects. However, there have been no reports concerning how muscle fiber characteristics change in the regions surrounding the lesion after excision of the carcinoma. In this study, we investigated myosin heavy chain (MyHC) isoforms at genetic levels in order to demonstrate the muscle fiber characteristics of the muscle tissues surrounding lingual carcinoma (the experimental group). High mobility group box 1 (HMGB1) was used as a marker to examine whether tongue cancer actually developed. MyHC-2a expression was high in the experimental group. Thus, the marked changes of muscle fiber characteristics, as seen in this study, were considered to be a biological reaction to changing muscle characteristics for regenerating or maintaining normal muscle tissues against the muscle atrophy caused by carcinoma.
\end{abstract}

Key words: Myosin heavy chain, Carcinoma of tongue, HMGB1, SCC VII, Mouse

\section{Introduction}

Myosin, one of the muscle-contracting proteins, is a major protein constituting muscle. Among others, myosin heavy chain (MyHC) is known to reflect muscle functions most clearly ${ }^{1)}$. Recently, MyHC isoforms that are majorly classified into fast muscle types (MyHC-2b, $-2 \mathrm{~d}$, and $-2 \mathrm{a}$ ) and slow muscle types (MyHC-1) according to their contractile rates ${ }^{2-4)}$. In addition, it has been suggested that composition ratio of these $\mathrm{MyHC}$ isoforms may characterize the muscle type. Based on these reports, investigation on the composition of $\mathrm{MyHC}$ isoforms is considered to reveal the muscle fiber characteristics.

Reports concerning the expressions of each MyHC isoform in the course of muscle growth and development were mainly about extremities, but recently, reports about head and neck muscles such as masticatory muscle can be $\operatorname{seen}^{5-13)}$. Gojo et al. and Shida et al. noted the phenomenon "weaning" seen in the course of growth, and observed the changes of muscle fiber

Corresponding to: Dr. Koji Sakiyama, Division of Anatomy, Department of Human Development and Fostering, Meikai University School of Dentistry, 1-1 Keyakidai, Sakado, Saitama, 350-0283, Japan; Tel \& Fax: +81-492792840; E-mail: sakiyama@dent.meikai.ac.jp characteristics of the mouse masseter at the protein level ${ }^{7,14)}$. There, they demonstrated that MyHC-2b, which produces high contractile rate and force, was highly expressed along with weaning, and thus considered that this resulted from functional changes of the masseter by chewing movement after weaning.

Maejima et al. and Yanagisawa et al. examined the changes of the muscle fiber characteristics of the upper and lower halves of the adult mouse tongue muscle before and after weaning, and confirmed marked changes of isoforms ${ }^{15,16)}$. Thus, marked functional changes before and after weaning, i.e., from suckling to chewing, were demonstrated to influence the characteristics of muscle fibers in the oral cavity. It has recently been speculated that hypofunction of the normal muscle as well as tissue loss affects the dysphagia after resective surgery of the lesion due to the development of the carcinoma of tongue ${ }^{17)}$. However, no investigation on the muscle fiber characteristics of the surrounding muscle tissue of the carcinoma of tongue has been reported.

In this study, squamous cell carcinoma (SCC) VII were injected into the tongue muscle to artificially develop the carcinoma of tongue, and their effects on the muscle fiber characteristics of the surrounding normal tongue muscle of the 
carcinoma of tongue were evaluated by genetic analyses for comparison with the normal tongue muscle.

The tongue muscle consists of fast muscle type $\mathrm{e}^{5,15,16)}$; thus, MyHC-2b and MyHC-2a, which is considered to have the highest and lowest contractile rates among fast muscle type $\mathrm{MyHC}$ isoforms, respectively, were selected to investigate the muscle fiber characteristics ${ }^{4)}$. HMGB1 was used as a marker to examine whether the carcinoma of tongue actually developed ${ }^{18)}$. HMGB1 is a DNA binding nonhistone protein that maintains chromosome structure and regulates gene transcription, and there have been many reports on it until now ${ }^{19-22)}$.

\section{Materials and Methods}

\section{Cell culture}

SCC VII cells, which are mouse oral SCC cell line, were used in this study. SCC VII cells are an established cell line originating from the oral floor division of the mouse. SCC VII cell is the poorly differentiated carcinoma.

Cells were cultured in Dulbecco's modified Eagle's medium (DMEM) (Sigma-Aldrich Co., St. Louis, MO) containing Penicilin-Streptomycin Solution (Sigma Aldrich Co.) and 10\% fetal bovine serum (FBS) (ICN Biomedicals Inc., Aurora, OH) in a humidified atmosphere of $5 \% \mathrm{CO}_{2}$ at $37^{\circ} \mathrm{C}$.

\section{Injection of SCC VII cells into BALB/cAJcl mice}

$500 \mu 1 \mathrm{SCC}$ VII cells $\left(1.0 \times 10^{6} / \mathrm{ml}\right)$ with serum-free DMEM were injected into the site at $5 \mathrm{~mm}$ from the tongue tip of nude male mice (BALB/cAJcl, 20g bodyweight). The mice were injected once a week, total 4 times, and were kept for another week. DMEM (Sigma-Aldrich Co) (FBS (-)) was injected to the control mice. All mice were fed powder diets.

Five mice each, total 20 mice, were used for mRNA expression analyses and immunohistochemical analysis after five weeks, we established carcinoma with tongue. According to the Experimental Animal Guideline of Meikai University School of Dentistry, the mice were deeply anesthetized with pentobarbital and killed. After SCC model mice were prepared, the tongues were removed at the root of tongue.

\section{Hematoxylin-Eosin (H-E) staining}

Following the conventional methods, serial sections were stained with $\mathrm{H}-\mathrm{E}$, then examined and photographed using a universal microscope (BX50; Olympus, Tokyo, Japan).

\section{Immunofluorescent staining}

Using a cryostat, $8 \mathrm{~mm}$-thick serial frozen sections were prepared in a direction perpendicular to the long axis of the tongue. In particular, central regions where the carcinoma of tongue was completely developed were observed. Immunostaining was performed in the following manner:
First, HMGB1 was used as a marker for the carcinoma of tongue. The blocking reagent was used $10 \%$ normal goat serum (Nichirei, Tokyo, Japan). As primary antibodies, the serial sections were treated with rabbit anti-HMGB1 antibody (Abcam, Cambridge, UK). As secondary antibodies, biotin-labeled antirabbit IgG antibody was used for HMGB1, then the sections were colored by $0.01 \%$ 3,3'-Diaminobenzidine tetrahydrochloride (Wako, Kumamoto, Japan).

Next, MyHC-2a and $2 b$ were used to confirm the characteristics of muscle. As primary antibodies, SC-71 (antiMyHC-2a) and BF-F3 (anti-MyHC-2b) (American Type Tissue Culture), anti-mouse monoclonal antibodies extracted from hybridoma cells, were used ${ }^{10,14-16,23)}$. More specifically, after culturing the hybridoma cells in DMEM (10\% FBS) medium at $37^{\circ} \mathrm{C}$ and $5 \% \mathrm{CO}_{2}$ for 72 hours, they were centrifuged, and the supernatants were used as antibodies.

As secondary antibodies, FITC-labeled goat anti-mouse IgG antibody (Novocastra Laboratories, Newcastle, UK) was used for SC-71, while Rhodamine-Conjugated GOAT F(AB')2 FRAGMENT TO MOUSE IgM (MP Biomedicals, Aurora, Ohaio) was used for BF-F3. Muscle fibers were examined using a confocal laser scanning microscope (MRC-1024/2P; Nippon Bio-Rad Lab. Tokyo. Japan). MyHC-2a-positive muscle fibers were defined as those labeled with FITC, while MyHC-2b-positive muscle fibers were defined as those labeled with RITC.

\section{RNA extraction and mRNA expression analysis using the LightCycler $^{\circledR}$}

MyHC-2b and MyHC-2a mRNAs were quantified using the LightCycler $^{\circledR}$ (Roche Diagnostics, Mannheim, Germany). mRNA was extracted using the Quick Prep micro mRNA Purification Kit (GE Healthcare, Amersham, UK), then cDNA was synthesized by the Ready-To-Go (GE Healthcare). After setting optimal conditions for all primers, the experiment was conducted according to the standard protocol of the LightCycler ${ }^{\circledR}$. Premix of LightCycler ${ }^{\circledR}$ Fast Start DNA Master SYBR Green I (Roche) was used as PCR reaction solution of hot-start PCR by the LightCycler ${ }^{\circledR}$. Dilution series were prepared using $4.0 \mathrm{ng} / \mathrm{ml}$ of PCR product as a concentrate solution, of which solutions diluted at 1:10 $10^{7}, 10^{8}$, and $10^{9}$ were used. Primers used were MyHC-2b, 2a, prepared by the Oligo 5primer design (Nihon Gene Research Laboratories Incse., Sendai, Japan) from each full-length DNA.

Primer sequences of MyHC-2b were as follows: 5'ACAGACTAAAGTGAAAGCC-3' (forward) and 5'CTCTCAACAGAAAGATGGAT-3' (reverse) (Accession: XM_126119). Primer sequences of MyHC-2a were as follows: 5'-CGATGATCTTGCCAGTAATG-3' (forward) and 5'TGATAACTGAGATACCAGCG-3' (reverse) (Accession: NM_144961). Two kinds of PCR mixtures (20 ml) of MyHC-2b, 2a, thus prepared, were added to the glass part of a capillary. Cycle 
Koji Sakiyama et al.: Characteristic of Muscle Fibers surrounding Carcinoma

Table1. Comparison of body weights between mice that developed the experimental group and the control group $(n=5)$.

A unit of weight: $g$ Marked reduction of body weight was confirmed due to the development of the carcinoma of tongue.

\begin{tabular}{llll}
\hline & Start & End & Weight gain \\
\hline Control & 19.5 & 26.5 & 7.0 \\
Experimental & 20.8 & 17.6 & $\boldsymbol{\Delta} 3.2$ \\
\hline
\end{tabular}

conditions were as follows: after $95^{\circ} \mathrm{C} 10 \mathrm{~min}, 50$ cycles of $95^{\circ} \mathrm{C}$ $10 \mathrm{sec}, 62^{\circ} \mathrm{C} 10 \mathrm{sec}$, and $72^{\circ} \mathrm{C} 7 \mathrm{sec}$. Gene amplification was performed according to the melting program of $70^{\circ} \mathrm{C}$ for $15 \mathrm{sec}$, and during the transition phase from $70^{\circ} \mathrm{C}$ to $95^{\circ} \mathrm{C}$, fluorescence was sequentially monitored at a rate of $0.1^{\circ} \mathrm{C} / \mathrm{sec}$. F1 (530 nm) was used for the fluorescence channel, and the gains indicated $89.9^{\circ} \mathrm{C}$ and $88.2^{\circ} \mathrm{C}$ for MyHC-2b and MyHC-2a, respectively. The quantities of each MyHC isoforms, calculated by the above method, were divided by the quantity of GAPDH that was used as a house keeping gene to obtain final mRNA expression levels. Primer sequences of GAPDH used are as follows: 5'TGAACGGGAAGCTCACTGG-3' (forward) and 5'TCCACCACCCTGTTGCTGTA-3' (reverse); Accession: NM_008084 $4^{8,11)}$.

Student's tukey's HSD test was used for statistical analysis in this study and a $\mathrm{p}$ value of $<0.05$ was considered significant.

\section{Results}

\section{Body weights}

Weight changes were compared between the mice that developed experimental group and the control group (Table1). In the control group, the weights had increased from $19.5 \mathrm{~g}$ to $26.5 \mathrm{~g}$. However, in the experimental group, the weights had decreased about $3.2 \mathrm{~g}$.

\section{H-E staining}

In the control group, the muscle fibers and the loose connective tissues were observed in the section. However, in the experimental group, the poorly differentiated carcinoma was observed in the deeply tongue. Furthermore, the muscle fibers were observed in the epithelium and the injected on artificial carcinoma tissue (Fig.1).

\section{Immunohistochemical analysis}

In the experimental group, HMGB1 was stained in and around the carcinoma of tongue region where cellular dysplasia was observed (Fig.2). Meanwhile, regions without cellular dysplasia, where HMGB1 was not stained, were determined as normal tongue muscle.

In the control group, many muscle fibers positive for MyHC$2 \mathrm{~b}$ were observed in the superior longitudinal muscle, while muscle
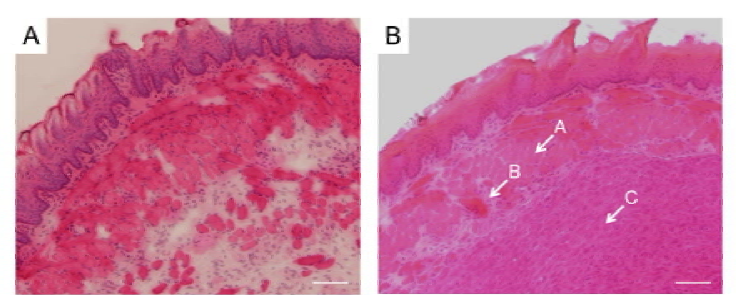

Figure 1. Histological observations from control group (A) and experimental group(B)

Scale bars: $100 \mu \mathrm{m}, \mathrm{H}-\mathrm{E}$ staining. a: normal muscle fiber; b:the carcinoma tissue infiltrated into muscle fibers; c: carcinoma tissue area.

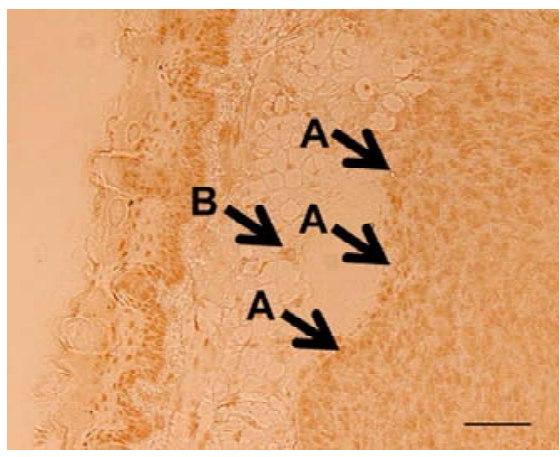

Figure 2. HMGB1 immunostaining image Scale bar: $100 \mu \mathrm{m}$ Arrows A: The border line of the carcinoma and muscle fibers. The carcinoma of tongue was stained positive by anti-HMGB1 antibody.

Arrow B: This is a nuclear of the muscle fiber. It was stained by anti- HMGB1antibody.
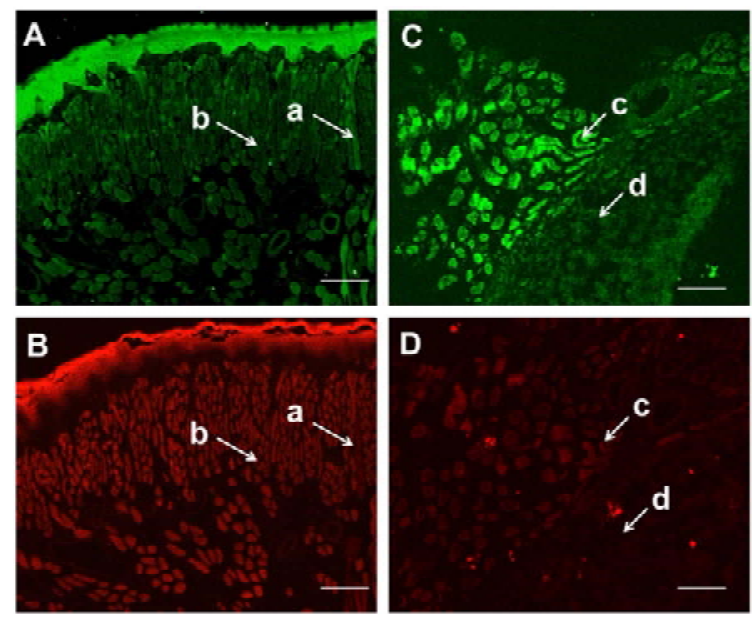

Figure 3. MyHC-2b and MyHC-2a immunostaining images Scale bars: $100 \mu \mathrm{m}$; A and B: control group; C and D: experimental group

$\mathrm{A}$ and C: anti-MyHC-2a antibodies; $\mathrm{B}$ and D: anti-MyHC-2b antibodies. a: vertical muscle; b: superior longitudinal muscle; $\mathrm{c}$ : normal muscle; d: carcinoma.

fibers positive for MyHC-2a were observed in the vertical muscle of tongue, which enters the superior longitudinal muscle (Fig.3). In the control group, the superior longitudinal muscles that have 

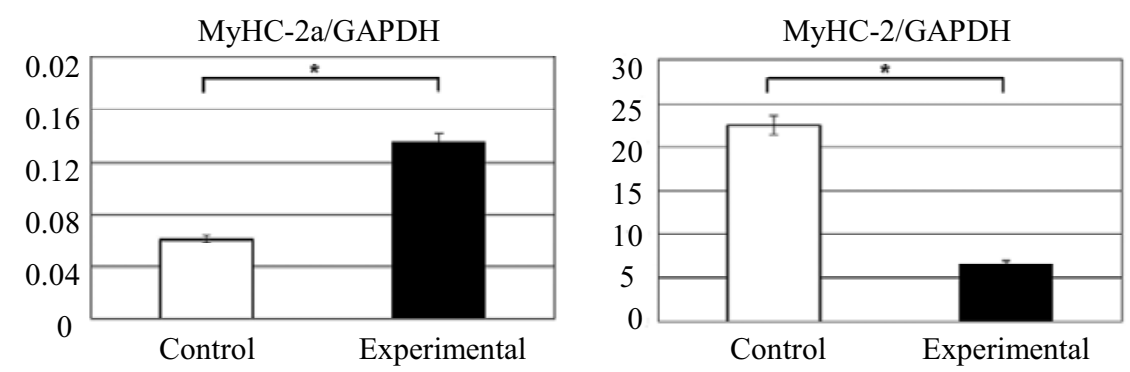

Figure 4. Expression level of MyHC-2b and MyHC-2a mRNA

The amount of MyHC-2b and MyHC-2a isoform calculated by the described in the text was divided by the amount of GAPDH, which was one of house keeping genes, to determine the mRNA expression. (mean: \pm S.D.) Statistical analysis: " $\mathrm{p}<0.05(\mathrm{n}=5)$.

masticatory function are characterized by MyHC-2b, suggesting that this function is decreased in mice with the carcinoma of tongue (Fig.3A and B).

In the experimental group, MyHC-2a was stained also in muscle cells surrounding the lesion to some extent, and was observed also in the superior longitudinal muscle, usually characterized by staining of MyHC-2b. In contrast, MyHC-2b was scarcely stained (Fig.3C and D).

Namely, in the experimental muscle tissues of mouse tongue, MyHC-2a expression was confirmed in the surrounding muscle fibers of the carcinoma of tongue, but MyHC-2b expression was scarcely observed. These findings differed from those of the control group.

\section{Analysis by the Light Cycler}

MyHC-2a and MyHC-2b mRNAs were confirmed in both the experimental and control groups. MyHC-2a expression was higher in the experimental group than control group. In contrast, MyHC$2 \mathrm{~b}$ expression was higher in the control group than in the experimental group $(p<0.05)$ (Fig.4). These results were significant difference.

\section{Discussion}

Growth of carcinoma is known to reduce body weight and fat $^{24,25)}$, and this weight reduction has been reported to result from consumption of skeletal muscles, before that of fat tissues ${ }^{26}$. Also in our study, weight reduction was confirmed in the experimental group.

HMGB1 has been reported to be expressed usually during muscle regeneration and development ${ }^{27)}$. In addition, the possibility that HMGB1 may be a key marker in other organs has been suggested ${ }^{18)}$. There has been no report on tongue cancer, but in this experiment, HMGB1 expression was high in the regions where tongue cancer, determined by cellular dysplasia, developed. In addition, surrounding muscle tissues without cellular dysplasia were also stained. Also, some signaling from cancer cells was considered to forecast the transition to cancer. The aim of the present study was to investigate the muscle fiber characteristics of the completely normal muscle tissues that surround cancer lesions; thus, HMGB1-stained regions were also determined to be abnormal tissues.

Cytokines and tumor factors have been reported to suppress the expression of myosin, a muscle gene products ${ }^{28-31}$. It has been suggested that selective regulation of muscle gene expression rather than consumption of muscles, induced by a tumor, plays a central role in reducing muscle proteins ${ }^{28}$.

In fact, MyHC-2b expression was observed in the normal tongue muscle, while little MyHC-2b expression and high MyHC2a expression were observed in the surrounding muscle fibers of the carcinoma of tongue. Analysis of MyHC-2b gene was expressed in the control group, but was very low in the experimental group. It is known that MyHC-2b usually appears at inactive muscle. However, in the experimental group, it might be that expression in MyHC-2b decreased because the regeneration of muscles became active for the carcinoma of tongue.

On the other hand, MyHC-2a expression was high in the experimental group, but low in the control group. MyHC-2a a common protein observed in the immature or regenerating muscles ${ }^{6}$; thus, the marked changes of muscle fiber characteristics found in this study were considered to be a biological reaction to change muscle characteristics to regenerate or maintain residual muscle tissues against the muscle consumption caused by tumor.

\section{Acknowledgements}

This study was supported by grants-in-aid for scientific research (50385142: K. Sakiyama) from the Ministry of Education, Culture, Sports, Science and Technology-Japan, by Japan Society for the Promotion of Science, 2008-2010.

\section{References}

1. Pette D and Staron RS. Cellular and molecular diversities of mammalian skeletal muscle fibers. Rev Physiol Biochem Pharmacol 116: 1-76, 1990

2. Brueckner JK, Itkis O and Porter JD. Spatial and temporal 
Koji Sakiyama et al.: Characteristic of Muscle Fibers surrounding Carcinoma

patterns of myosin heavy chain expression in developing rat extraocular muscle. J Muscle Res Cell Motil 17: 297-312, 1996

3. Hori A, Ishihara A, Kobayashi S and Ibata Y. Immunohistochemical classification of skeletal muscle fibers. Acta Histochem Cytochem 31: 375-384, 1998

4. Schiaffino S and Reggiani C. Molecular diversity of myofibrillar proteins: Gene regulation and functional significance. Physiol Rev 76: 371-423, 1996

5. Abe S, Maejima M, Watanabe H, Shibahara T, Agematsu H, Doi T, Sakiyama K, Usami A, Gojo K, Hashimoto M, Yoshinari $\mathrm{M}$ and Ide Y. Muscle-fiber characteristics in adult mouse tongue muscles. Anat Sci Int 77: 145-148, 2002

6. Doi $\mathrm{T}, \mathrm{Abe} \mathrm{S}$ and Ide $\mathrm{Y}$. Masticatory function and properties of masseter muscle fibers in microphthalmia ( $\mathrm{mi} / \mathrm{mi})$ mice during postnatal development. Ann Anat 185: 435-440, 2003

7. Gojo S, Abe S and Ide Y. Characteristics of myofibers in the masseter muscle of mice during postnatal growth. Anat Histol Embryol 31: 105-112, 2002

8. Kurokawa K, Abe S, Sakiyama K, Takeda T, Ide Y and Ishigami K. Effects of stretching stimulation with different rates on the expression of MyHC mRNA in mouse cultured myoblasts. Biomed Res 28: 25-31, 2007

9. Lee WH, Abe S, Kim HJ, Usami A, Honda A, Sakiyama K and Ide Y. Characteristics of muscle fibers reconstituted in the regeneration process of masseter muscle in an mdx mouse model of muscular dystrophy. J Muscle Res Cell Motil 27: 235-240, 2006

10. Okubo K, Abe S, Usami A, Agematsu H, Nakamura H, Hashimoto $\mathrm{M}$ and Ide $\mathrm{Y}$. Changes in muscle-fiber properties of the murine digastric muscle before and after weaning. Zoolog Sci 23: 1079-1084, 2006

11. Sakiyama K, Abe S, Tamatsu Y and Ide Y. Effects of stretching stress on the muscle contraction proteins of skeletal muscle myoblasts. Biomed Res 26: 61-68, 2005

12. Suzuki K, Abe S, Kim HJ, Usami A, Iwanuma O, Okubo H and Ide Y. Changes in the muscle fibre properties of the mouse temporal muscle after weaning. Anat Histol Embryol 36: 103-106, 2007

13. Usami A, Abe S and Ide Y. Myosin heavy chain Isoforms of the murine masseter muscle during pre- and post-natal development. Anat Histol Embryol 32: 244-248, 2003,

14. Shida T, Abe S, Sakiyama K, Agematsu H, Mitarashi S, Tamatsu Y and Ide Y. Superficial and deep layer muscle fiber properties of the mouse masseter before and after weaning. Arch Oral Biol 50: 65-71, 2005

15. Maejima M, Abe S, Sakiyama K, Agematsu H, Hashimoto $\mathrm{M}$, Tamatsu $\mathrm{Y}$ and Ide $\mathrm{Y}$. Changes in the properties of mouse tongue muscle fibres before and after weaning. Arch Oral Biol 50: 988-993, 2005
16. Yanagisawa N, Abe S, Agematsu H, Sakiyama K, Usami A, Tamatsu Y and Ide Y. Myosin heavy chain composition of tongue muscle in microphthalmic $(\mathrm{mi} / \mathrm{mi})$ mice before and after weaning. Ann Anat 188: 329-336, 2006

17. Logemann JA, Rademaker AW, Pauloski BR, Lazarus CL, Mittal BB, Brockstein B, MacCracken E, Haraf DJ, Vokes EE, Newman L A and Liu D. Site of disease and treatment protocol as correlates of swallowing function in patients with head and neck cancer treated with chemoradiation. Head Neck 28: 64-73, 2006

18. Zeh HJ $3_{\text {rd }}$ and Lotze MT. Addicted to death: invasive cancer and the immune response to unscheduled cell death. J Immunother 28: 1-9, 2005

19. Evans A, Lennard TW and Davies BR. High-mobility group protein $1(\mathrm{Y})$ : metastasis-associated or metastasis-inducing? J Surg Oncol 88: 86-99, 2004

20. Ito I, Mitsuoka N, Sobajima J, Uesugi H, Ozaki S, Ohya K and Yoshida M. Conformational difference in HMGB1 proteins of human neutrophils and lymphocytes revealed by epitope mapping of a monoclonal antibody. J Biochem 136: 155-162, 2004

21. Song MJ, Hwang S, Wong W, Round J, Martinez-Guzman D, Turpaz Y, Liang J, Wong B, Johnson RC, Carey M and Sun R. The DNA architectural protein HMGB1 facilitates RTA-mediated viral gene expression in gamma-2 herpesviruses. J Virol 78: 12940-12950, 2004

22. Takata K, Kitamura Y, Tsuchiya D, Kawasaki T, Taniguchi T and Shimohama S. High mobility group box protein-1 inhibits microglial Abeta clearance and enhances Abeta neurotoxicity. J Neurosci Res 78: 880-891, 2004

23. Yoshii M, Sakiyama K, Abe S, Agematsu H, Mitarashi S, Tamatsu $Y$ and Ide Y. Changes in the myosin heavy chain $2 \mathrm{a}$ and $2 \mathrm{~b}$ isoforms of the anterior belly of the digastric muscle before and after weaning in mice. Anat Histol Embryol 37: 147-152, 2008

24. Boddy JJ. The syndrome of anorexia-cachexia. Curr Opin Oncol 11: 255-260, 1999

25. Muscaritoli M, Bossola M, Aversa Z, Bellantone R and Rossi Fanelli F. Prevention and treatment of cancer cachexia: new insights into an old problem. Eur J Cancer 42: 31-41, 2006

26. Tisdale MJ. Cachexia in cancer patients. Nat Rev Cancer 2: 862-871, 2002

27. Roberta P, Maurilio S, Francesco D. M, Rossana T, Sara C, Anna M, Giulio C and Marco E. B. Extracellular HMGB1, a signal of tissue damage, induces mesoangioblast migration and proliferation. The Rockefeller University Press 164: 441449, 2004

28. Acharyya S, Ladner KJ, Nelsen LL, Damrauer J, Reiser PJ, Swoap S and Guttridge DC. Cancer cachexia is regulated by 
J.Hard Tissue Biology Vol. 22(2):215-220, 2013

selective targeting of skeletal muscle gene products. J Clin Invest 114: 370-378, 2004

29. Alleva LM, Yang H, Tracey KJ and Clark IA. High mobility group box 1 (HMGB1) protein: Possible amplification signal in the pathogenesis of falciparum malaria. Trans R Soc Trop Med Hyg 99: 171-174, 2005

30. Palumbo R, Sampaolesi M, De Marchis F, Tonlorenzi R, Colombetti S, Mondino A, Cossu G and Bianchi M. E.
Extracellular HMGB1, a signal of tissue damage, induces mesoangioblast migration and proliferation. J Cell Biol 164: 441-449, 2004

31. Swarnali A, Katherine J. L. Lori L. N, Jeffrey D, Peter JR, Steven $\mathrm{S}$ and Denis C. G. Cancer cachexia is regulated by selective targeting of skeletal muscle gene products. J Clin Invest 114: 370-378, 2004 